\title{
PHYSIOLOGICAL EXPEDITION TO THE ANTARCTIC
}

\author{
By DR. L. G. C. E. PUGH \\ Medical Research Council Laboratories, Hampstead, London, N.W.3
}

\begin{abstract}
A $\mathrm{N}$ Anglo-American Physiological Expedition will $A$ be leaving shortly for the Antarctic to carry out studies connected with human acclimatization to cold. The party will assemble in California at the end of November and travel from there via New Zealand to Ross Island at the edge of the Antaretic Continent. They will be taking part in Operation Deep Freeze II of the International Geophysical Year.

The party is being transported by air under arrangements made by the Office of Naval Research, U.S. Navy, and by the United States Military Air Transport. In this way the team hopes to accomplish a programme in four months, which would otherwise require wintering in the Antarctic and four months travelling.

In spite of common experience that one grows accustomed to cold, as well as anthropological testimony, very little objective evidence in support of cold acclimatization has so far been found. Studies have hitherto been hampered by lack of methods for measuring metabolism and changes in body temperature continuously over periods of days at a time.
\end{abstract}

Major J. M. Adam, R.A.M.C., and the author, whose participation has been made possible by a generous grant from the Wellcome Trust, will be carrying out studies of this nature on themselves and on members of other expeditions already in the Antarctic. They will use apparatus developed by Mr. H. S. Wolff at the Medical Research Council's Division of Human Physiology at Hampstead, which will enable them to obtain prolonged records of the kind required. Samples of blood plasma will also be collected for lipid analysis.

It is well known that the fatty composition of the blood and tissue lipids of hibernating animals during winter is different from that during summer. The differences are such that the degree of unsaturation of the fatty acids of the lipids is higher, and the melting point lower, in winter than in summer. A preliminary investigation of the blood lipids of persons exposed to intense cold during the British North Greenland Expedition was carried out by Dr. J. E. Lovelock, of the National Institute for Medical Research, Mill Hill. The results suggested that similar changes to those found with hibernating animals may occur in the blood lipids of human beings. Dr. Lovelock will continue his studies on the samples of blood plasma brought back from the Antarctic.

A further reason for interest in the problem of blood lipids is the finding that the fatty-acid composition of the plasma lipids of patients with coronary artery disease has shown differences between them and normal subjects similar to those observed in the winter on the Greenland expedition. This similarity could imply that the regional and social differences in the incidence of coronary artery disease may be as much a consequence of environment as of diet.

The American members of the expedition, led by Dr. Nello Pace, of the University of California, are interested primarily in physiological reactions to stress. The pattern of adrenal cortical response to varying stresses has already been studied by this group on front-line combatants in the Korean War as well as in other stress situations. Surgeon-Commander Miller, of the United States Navy, will be studying the epidemiology of upper respiratory infections among personnel in the Antarctic bases on Ross Island. Antarctic personnel are said to remain almost entirely free of colds, except following the arrival of ships or on opening packing cases and mail. In ordinary communities this mode of infection, namely by contact with contaminated objects, is thought to be unusual, at least as regards the common cold virus.

Some of the expedition's equipment was recently on view at the Medical Research Council's Laboratories at Hampstead. It included sledging rations incorporating a variety of new dehydrated meats and other foods, packaged entirely in plastic bags, thus avoiding the use of tins. The cooking equipment employs propane in place of paraffin, and is claimed to give nearly 80 per cent heating efficiency compared with 40 per cent for the conventional paraffin stoves used previously. Also on view were newly designed sledges and various types of protective clothing and other equipment. It was pointed out that this expedition could afford to be more experimental in its approach to problems of equipment than other expeditions, because it will not be called on to move more than two hundred miles from a well-equipped base.

\section{OBITUARIES}

Prof. G. H. Wooldridge

George Henry Wooldridge, emeritus professor of veterinary medicine and the doyen of the Royal Veterinary College, died on August 30 following an operation; he was eighty years of age. For some years a gradual failure of his eyesight had caused him to retire from active participation in the work of the many bodies and societies which he had served so well for many years, and to relinquish his consultation practice in which his services had been in great demand. Mentally and physically he remained in good health, and the illness which caused his death was of a relatively short duration.

$\mathrm{He}$ was born at Stoke-on-Trent and was very proud to be a Staffordshire man. He was educated at St. Peter's School at Stoke and at Orme Boys' School, Newcastle-under-Lyme. After serving as junior assistant at E.M. School at Newcastle-underLyme (1892-93) he decided to enter the veterinary profession. As was the custom in those days, he was placed as pupil with J. Wilson, of Nantwich, in 1893 , before entering the Royal Veterinary College in 1895. 